\title{
Appraisal of acute oral toxicity of glucuronoxylan hydrogel from Mimosa pudica seeds
}

\author{
Gulzar Muhammad ${ }^{1,2}$, Muhammad Ajaz Hussain*2, Muhammad Umer Ashraf ${ }^{3}$, \\ Muhammad Naeem-ul-Hassan², Syed Nasir Abbas Bukhari*4
}

\begin{abstract}
${ }^{1}$ Department of Chemistry, GC University Lahore, Pakistan, ${ }^{2}$ Department of Chemistry, University of Sargodha, Sargodha, Pakistan, ${ }^{3}$ Faculty of Pharmacy, University of Sargodha, Sargodha, Pakistan, ${ }^{4}$ Department of Pharmaceutical Chemistry, College of Pharmacy, Jouf University, Aljouf, Sakaka, Saudi Arabia
\end{abstract}

\begin{abstract}
Glucuronoxylan hydrogel $(\mathrm{GXH})$ isolated from $M$. pudica seeds was assessed for acute toxicology in albino mice that were alienated into four groups. Three groups, i.e., II, III and IV received GXH at a dose of 1,2 and $5 \mathrm{~g} / \mathrm{kg}$, respectively while group I was retained untreated and provided routine diet. After administering GXH, mice were examined for vomiting, diarrhea, allergy and tremors for 8 h. All animals were carefully observed for food and water consumption at 1, 2, 3, 7 and 14 day after administering GXH. At the end of studies, blood samples were drawn for investigation of hematological and biochemical parameters. All animals were sacrificed, relative body weight of vital organs was calculated and their histopathology was studied. It was concluded that there was insignificant difference in body weight, behavioral pattern, food and water intake among treated and control groups. Haematology and biochemistry of blood samples from all groups were found analogous. Histopathological evaluation of vital body organs exhibited no lesions in all groups. Ocular, cardiac and dermal safety of GXH was also established on albino rabbits.
\end{abstract}

Keywords: Glucuronoxylan. Acute toxicity. Histopathology. Toxicology. Mimosa pudica.

\section{INTRODUCTION}

Mimosa pudica L. is a medicinal plant of family Mimosaceae which is cosmopolitan in nature and contains phytochemicals such as alkaloids, steroids, terpenoids, tannins and flavonoids (Muhammad et al., 2016; Bum et al., 2004; Dinda et al., 2006). The plant is traditionally promised to cure stomach disorders, haemorrhoids, respiratory troubles, fever, snake bites, anxiety, dysentery and inflammatory problems (Molina, Contreras, Tellez-Alcantara, 1999; Khalid et al., 2011). The seeds of $M$. pudica (MP) extrude glucuronoxylan hydrogel in water, which mainly consists of D-xylose and D-glucuronic acid (Muhammad et al., 2015; Saraswat, Pokharkar, 2012).

\footnotetext{
*Correspondence: M. A. Hussain. Department of Chemistry, University of Sargodha, Sargodha, 40100 - Pakistan. Tel: + 92 3468614959. E-mail address: majaz172@yahoo.com (M. A. Hussain)

S. N. A. Bukhari. Department of Pharmaceutical Chemistry, College of Pharmacy, Aljouf University, Aljouf, Sakaka 2014, Saudi Arabia. E-mail address: sbukhari@ju.edu.sa
}

Irrespective of low bioavailability and higher frequency of doses, drugs are frequently administered to patients via oral route (Zhang et al., 2004; Gupta, Shivakumar, 2009). To overcome this problem, gastroretentive drug delivery systems are developed (Maderuelo, Zarzuelo, Lanao, 2011) using muco-adhesive polymers (Ponchel, Irache, 1998), floating ion exchange resins (Atyabi et al., 1996) and water swellable hydrogels (Chen et al., 2000; Saiyed et al., 2015).

Polysaccharide hydrogels hold sufficient quantity of water owing to the existence of hydrophilic functional groups $\left(-\mathrm{OH},-\mathrm{COOH},-\mathrm{CONH}_{2}\right)$. The water retention tendency also depends upon elasticity of network, degree of crosslinking and permeability of polymer (Hoffman, 2012). Hydrogels are smart, intelligent, biodegradable, biocompatible, abundant and non-toxic polymers which are used in cosmetics, agronomy, medicines, gardening, engineering, immobilization of enzymes and diapers (Hussain et al., 2016; Good, Bowman, Davis, 2004; Liu et al., 2007; Ashraf et al., 2017). They are particularly potential candidates for developing targeted delivery 
because of $\mathrm{pH}$ responsive nature (Haseeb et al., 2016; Zou, Zhao, Ye, 2015; Muhammad et al., 2015).

Herein, we are aimed to establish oral safety of an innovative, super porous and intelligent polysaccharide, GXH extruded from MP seeds. The study of acute toxicity of GXH was carried out in agreement to United State Pharmacopeia-NF regulatory requirement of excipients. The study protocol approved by the research ethics committee of University of Sargodha, Sargodha Pakistan was strictly followed (Ref. No. 75-2014/PREC).

\section{MATERIAL AND METHODS}

\section{Material}

MP seeds procured from local market were cleaned and stored in air tight container after taxonomic authentication from Department of Biological Sciences, University of Sargodha, Sargodha, Pakistan.

\section{Animals}

For the evaluation of toxicological studies, Swiss albino mice (24-29 g) of either sex and albino rabbits (1110-1180 g) were taken from the animal house of University of Sargodha, Sargodha, Pakistan. After careful inspection of animals, they were placed in uncontaminated cages at room temperature. The animals were regularly brought to sunlight and administered with routine diet and water. All tests and procedures were according to the Good Laboratory Practice (GLP) regulations as described by United States Food and Drug Administration (USFDA) and Organization for Economic Co-operation and Development (OECD) Test Guidelines 425 (Up and Down Procedure) (Chen et al., 2006). Before starting experiment, approval was taken from research ethics committee of University of Sargodha, Sargodha, Pakistan (Ref. No. 75-2014/ PREC). Four groups of animals (with three animals each) were chosen for toxicological evaluation. Group I was fed with routine diet while other three groups (II-IV) were administered with 1,2 and $5 \mathrm{~g} / \mathrm{kg}$ dose of GXH, respectively.

\section{Isolation of hydrogel}

MP seeds extrude hydrogel when soaked in water for $12 \mathrm{~h}$. Mild heating $\left(50^{\circ} \mathrm{C}\right)$ was carried out for $30 \mathrm{~min}$ to improve the yield of hydrogel. The GXH was detached from seeds using cotton cloth and then washed with $n$-hexane to get rid of lipophilic substances. GXH was dried at $50^{\circ} \mathrm{C}$ in oven and then kept in container provided with screwed lid.

\section{Evaluation of toxicology}

Before toxicological assessment, animals (7-8 weeks) were retained in laboratory for one week for adaptation of environment. After fasting of $12 \mathrm{~h}$, groups II-IV were administered with single oral dose of GXH in pellets, dosing 1,2 and $5 \mathrm{~g} / \mathrm{kg}$ body weight per oral route, respectively. After $1 \mathrm{~h}$ of administration of GXH, mice were given access to tap water and normal diet. The study was carried out for 14 days. Group I animals were left untreated and were given access to normal diet and water.

\section{Parameters to be assessed}

During 14 days study, animals were routinely and cautiously observed for any toxicity, death, sickness, diarrhea, dizziness, salivation and tremors. Furthermore, mice were also witnessed for any change in fur, skin, mucus membranes, eyes and behavior.

\section{Estimation of body weight, consumption of food and water}

On $1^{\text {st }}, 2^{\text {nd }}, 3^{\text {rd }}, 7^{\text {th }}$ and $14^{\text {th }}$ days, weight of animals of all groups was noted with great care. Additionally, food and water intake of animals of all groups (I-IV) were also observed.

\section{Ocular irritation}

Six albino rabbits of either sex were chosen for eye irritation test. For assessment of ocular irritation, fine suspension of GXH in water was placed in conjunctiva of right eye of each albino rabbit. Eye lids were gently closed with fingers to keep GXH in eyes for a while. Ocular irritation was observed after 1, 24, 48 and $72 \mathrm{~h}$ after administering GXH in eyes and results were compared with untreated left eye of each rabbit.

\section{Acute dermal toxicity}

Before acute dermal toxicity evaluation, six healthy white albino rabbits were carefully observed for any sign of ailment. After shaving hairs of rabbits, thick paste of GXH applied on a 4 ply gauze pad $\left(4^{\prime \prime} \times 4 "\right)$ and affixed it on the rabbit's skin with Micropore ${ }^{\mathrm{TM}}$ tape. The pad was detached after 12, 24, 36 and $48 \mathrm{~h}$ to observe any variation in skin colour of treated animals from control. 


\section{Relative organ body weight}

To observe any lesion in vital organs, mice were sacrificed on day $15^{\text {th }}$, dissected, and heart, kidney, lungs, spleen, liver and gastro intestinal tract (GIT) were removed. Absolute weight of organs of both control and test animals was determined and relative organ weight (ROW) was computed using formula (Sahgal et al., 2010) given in Eq. (1). ROW of both treated and control group animals was also compared.

$$
\text { ROW }=\frac{\text { Absolute weight of organ }}{\text { Total body weight of mice at the end of study }}
$$

\section{Histopathology of vital organs}

Animals were sacrificed to separate their vital organs for histopathological evaluation. The body organs such as heart, liver, kidney, intestinal mucosa and spleen were kept in formalin $(10 \% \mathrm{v} / \mathrm{v})$. To examine cellular structures, small part of each organ was cut with rotary microtome. Slides were prepared by staining with eosin and heamatoxylin dyes.

\section{Hematological and biochemical analysis of blood}

At the end of study, blood samples were taken from animals before they were sacrificed to study hematology and biochemistry of blood. Posterior vena cava was selected for collection of sample using $22 \mathrm{G}$ syringe by cardiac puncture. Sahli heamometer was used to determine hemoglobin in the blood. Likewise, counting of RBCs, WBCs and platelets was commenced. The liver profile, renal function and lipid profile was judged by biolyser.

\section{Safety pharmacology study}

As per guidelines of International Conference of Harmonization, pharmacological attributes of each excipient are obligatory either with toxicology or alone (ICH, 2005). Modified Langendorff technique was employed to evaluate toxicology of GXH on heart of albino rabbits. Rabbits were made unconscious by injecting heparin (1000 IU). The heart with aorta $(1 \mathrm{~cm})$ separated by surgery was washed with oxygenated Ringers solution ( $\mathrm{NaCl}, 45.0 \mathrm{~g}$; $\mathrm{NaHCO}_{3}, 1.0 \mathrm{~g}$; D-glucose, $5.0 \mathrm{~g}$; $\mathrm{KCl}, 2.1 \mathrm{~g} ; \mathrm{CaCl}_{2} \cdot 2 \mathrm{H}_{2} \mathrm{O}, 1.6 \mathrm{~g}$; in $5 \mathrm{~L}$ of distilled water). The squeezing of heart was done repetitively to remove the left over blood from heart before they were transferred to the perfusion apparatus (Radnoti Isolated Heart System,
AD Instrument, Australia). The bubbling of mixture of oxygen $(95 \%)$ and carbon dioxide $(5 \%)$ through heart was carried out after fixing heart with glass cannula. Before administration of GXH (0.001, 0.01, 0.1 and $1 \mathrm{mg} / \mathrm{mL})$, hearts were stabilized for $30 \mathrm{~min}$. The force of contraction, heart rate and perfusion pressure were explored before and after the drug administration.

With the help of threads, heart was connected to Palmer clip on one end and force displacement transducer (MLT 844; AD Instruments, Australia) on the other end for the investigation of mechanical force of contraction of heart. The heart rate was noted using Lab Chartpro 5 software (AD Instruments, Australia). The intensity of signals from force transducer increased before sending to an analog-to-digital converter (Power Lab Data Acquisition and Analysis system of AD Instruments, Australia).

\section{Statistical analysis}

The experimental data obtained was shown as mean \pm SEM and discrepancies in experimental data among control and treated groups were expressed using one way ANOVA (Turkeys multiple comparison test) and probability value $(<0.05)$ was considered significant.

\section{RESULTS AND DISCUSSION}

\section{Assessment of Corporeal factors}

Careful observations revealed that health of the mice was satisfactory throughout the study and no mortality was noticed. The eyes, skin and mucosa were also normal. Moreover, no alteration in behaviour, sleep, tremors, diarrhea and salivation was discerned.

\section{Appraisal of body weight, food and water intake}

No significant variations in weight of mice of treated and control group animals were observed. A slight decrease during first three days of study was noted. This is because of low food and water intake during first three days. After $3^{\text {rd }}$ day, increase in average weight of animals was noticed. No significant difference was witnessed in food and water intake and body weight among the animals of control and treated groups after first day (Table I).

\section{Irritation to eyes and skin}

According to guidelines of United States Pharmacopoeia, safety of an excipient should be evaluated 
TABLE I - Results of body weight, and food and water consumption by control and treated groups of albino mice

\begin{tabular}{|c|c|c|c|c|c|}
\hline S/No & Clinical Observations & Group-I control & $\begin{array}{c}\text { Group-II Treated } \\
(1 \mathrm{~g} / \mathrm{kg})\end{array}$ & $\begin{array}{c}\text { Group-III Treated } \\
(2 \mathrm{~g} / \mathrm{kg})\end{array}$ & $\begin{array}{c}\text { Group-IV Treated } \\
(5 \mathrm{~g} / \mathrm{kg})\end{array}$ \\
\hline \multirow[t]{7}{*}{1} & Body weight & & & & \\
\hline & Before treatment & $27.5 \pm 0.63$ & $26.4 \pm 0.61$ & $27.4 \pm 0.51$ & $28.56 \pm 0.81$ \\
\hline & Day 1 & $26.96 \pm 0.67$ & $26.0 \pm 0.69$ & $26.5 \pm 0.57$ & $27.97 \pm 0.83$ \\
\hline & Day 2 & $27.07 \pm 0.57$ & $26.1 \pm 0.68$ & $26.7 \pm 0.51$ & $28.03 \pm 0.83$ \\
\hline & Day 3 & $27.23 \pm 0.71$ & $26.3 \pm 0.68$ & $26.73 \pm 0.70$ & $28.22 \pm 0.91$ \\
\hline & Day 7 & $27.8 \pm 0.68$ & $26.53 \pm 0.73$ & $27.03 \pm 0.90$ & $28.53 \pm 0.91$ \\
\hline & Day 14 & $28.1 \pm 0.76$ & $26.9 \pm 0.81$ & $27.44 \pm 0.87$ & $28.84 \pm 0.92$ \\
\hline \multirow[t]{7}{*}{2} & Food intake & & & & \\
\hline & Before treatment & $2.10 \pm 0.13$ & $2.20 \pm 0.12$ & $2.40 \pm 0.18$ & $2.74 \pm 0.12$ \\
\hline & Day 1 & $1.63 * \pm 0.12$ & $1.70 * \pm 0.13$ & $1.83 * \pm 0.17$ & $2.22 * \pm 0.14$ \\
\hline & Day 2 & $1.87 \pm 0.18$ & $2.06 \pm 0.14$ & $2.21 \pm 0.13$ & $2.52 \pm 0.14$ \\
\hline & Day 3 & $1.96 \pm 0.13$ & $2.30 \pm 0.14$ & $2.28 \pm 0.14$ & $2.71 \pm 0.13$ \\
\hline & Day 7 & $2.10 \pm 0.16$ & $2.41 \pm 0.13$ & $2.45 \pm 0.15$ & $2.78 \pm 0.10$ \\
\hline & Day 14 & $2.13 \pm 0.13$ & $2.45 \pm 0.13$ & $2.50 \pm 0.11$ & $2.83 \pm 0.13$ \\
\hline \multirow[t]{7}{*}{3} & Water intake & & & & \\
\hline & Before treatment & $11.3 \pm 0.23$ & $11.56 \pm 0.81$ & $12.1 \pm 0.63$ & $12.16 \pm 0.70$ \\
\hline & Day 1 & $10.7 \pm 0.35$ & $10.96 \pm 0.82$ & $11.66 \pm 0.61$ & $10.96 * \pm 0.61$ \\
\hline & Day 2 & $11.5 \pm 0.38$ & $11.7 \pm 0.79$ & $12.06 \pm 0.47$ & $11.93 \pm 0.73$ \\
\hline & Day 3 & $11.6 \pm 0.42$ & $11.93 \pm 0.81$ & $11.9 \pm 0.78$ & $12.43 \pm 0.55$ \\
\hline & Day 7 & $11.6 \pm 0.58$ & $12.16 \pm 0.58$ & $12.4 \pm 0.73$ & $12.8 \pm 0.78$ \\
\hline & Day 14 & $12.0 \pm 0.34$ & $12.30 \pm 0.84$ & $12.53 \pm 0.80$ & $12.6 \pm 0.78$ \\
\hline
\end{tabular}

Consumption of water and food, and body weight are depicted as mean \pm SEM

before its use in oral or dermal formulations. The results displayed that GXH caused no irritation to eyes and skin of rabbits. It was also noted that color of eyes of rabbits of all groups were same and exhibited no redness, corneal opacity and iritis for $72 \mathrm{~h}$ (Table II). For grading, scores were calculated using Kay and Calandra eye irritation scale (Kay, Calandra, 1962).

Furthermore, dermal application of GXH instigated no rashes, inflammation, redness and swelling among rabbits of control and treated groups.

\section{Histopathology of vital organs and their relative weights}

On $15^{\text {th }}$ day, vital organs like heart, liver, kidneys, spleen and stomach were separated and weighed cautiously. The weights of all vital body organs were calculated relative to the body weight of mice. The relative weights of organs showed insignificant differences among control and treated mice (Table III). Histopathological studies exhibited no lacerations, indicating the potential utilization of GXH in oral formulations is non-toxic (Figure 1a-e).

\section{Blood biochemistry and hematology}

Hematological study of blood samples taken from mice of different groups revealed that number of white blood cells (WBCs), red blood cells (RBCs), platelets and amount of hemoglobin were observed to be in normal ranges. Insignificant difference in hematological parameters was observed among different groups of mice. Biochemistry of blood depicted normal functioning of liver and kidney. Amounts of serum triglycerides were also normal (Table IV). Hematology and biochemistry of blood samples suggested non-toxic nature of GXH in oral formulations.

\section{Safety pharmacology}

Cardiac safety of GXH excipients was evaluated using standard procedure reported in International 
TABLE II - Scores calculated using Kay and Calandra eye irritation scale

\begin{tabular}{llllll}
\hline \multirow{2}{*}{ Studied groups } & Ocular observations & $\mathbf{0 1}$ & $\mathbf{2 4}$ & $\mathbf{4 8}$ & $\mathbf{7 2}$ \\
\cline { 2 - 5 } Group I & Corneal opacity & 0 & 0 & 0 & 0 \\
& Iritis & 0 & 0 & 0 & 0 \\
& Conjunctivitis & 0 & 0 & 0 & 0 \\
& Severity (MMTS) & 0 & 0 & 0 & 0 \\
\hline Group II & Corneal opacity & 0 & 0 & 0 & 0 \\
& Iritis & 0 & 0 & 0 & 0 \\
& Conjunctivitis & 0 & 0 & 0 & 0 \\
\hline Group III & Severity (MMTS) & 0 & 0 & 0 & 0 \\
& Corneal opacity & 0 & 0 & 0 \\
& Iritis & 0 & 0 & 0 & 0 \\
& Conjunctivitis & 0 & 0 & 0 & 0 \\
\hline Group IV & Severity (MMTS) & 0 & 0 & 0 & 0 \\
& Corneal opacity & 0 & 0 & 0 & 0 \\
& Iritis & 0 & 0 & 0 & 0 \\
\hline
\end{tabular}
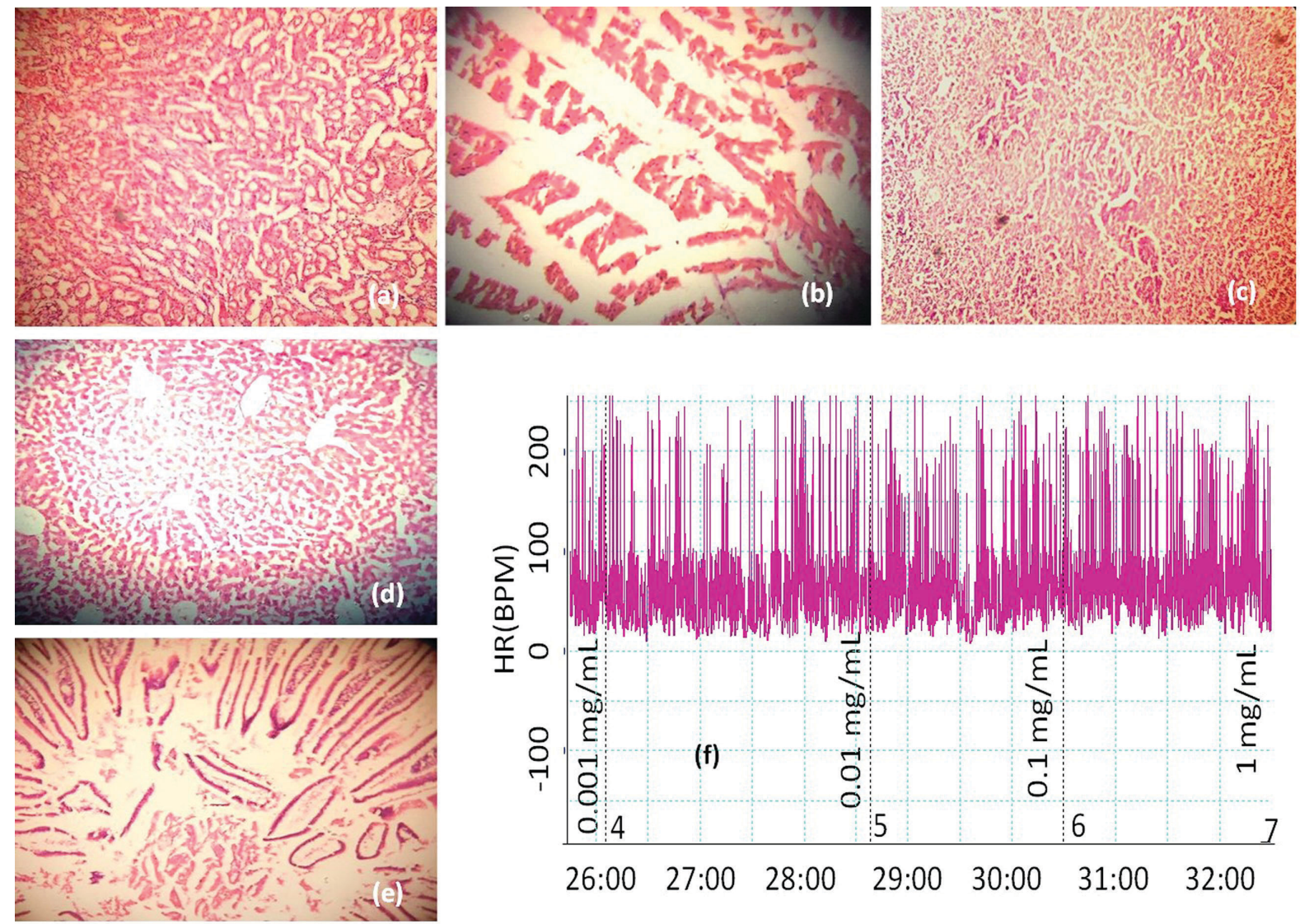

FIGURE 1 - Histopathology of various vital body organs of mice (a) intestine (b) heart (c) spleen (d) liver (e) kidney and (f) effect of various GXH concentrations on heart rate. 
TABLE III - Relative weight of vital body organs of mice

\begin{tabular}{lcccccc}
\hline Groups & Dose & Heart & Liver & Kidney & Spleen & Stomach \\
\hline Group-I & & $0.47 \pm 0.01$ & $1.67 \pm 0.11$ & $0.80 \pm 0.02$ & $0.57 \pm 0.13$ & $1.24 \pm 0.03$ \\
Group-II & $1 \mathrm{~g} / \mathrm{kg}$ & $0.49 \pm 0.02$ & $1.71 \pm 0.03$ & $0.83 \pm 0.01$ & $0.64 \pm 0.05$ & $1.27 \pm 0.13$ \\
Group-III & $2 \mathrm{~g} / \mathrm{kg}$ & $0.45 \pm 0.01$ & $1.61 \pm 0.04$ & $0.77 \pm 0.03$ & $0.54 \pm 0.10$ & $1.15 \pm 0.05$ \\
Group-IV & $5 \mathrm{~g} / \mathrm{kg}$ & $0.52 \pm 0.03$ & $1.78 \pm 0.13$ & $0.89 \pm 0.04$ & $0.70 \pm 0.04$ & $1.33 \pm 0.06$ \\
\hline
\end{tabular}

Organ weight is expressed as relative organ body weight \pm SEM

TABLE IV - Hematology and blood biochemistry of mice

\begin{tabular}{|c|c|c|c|c|}
\hline Test & Group-I control & $\begin{array}{c}\text { Group-II Treated } \\
(1 \mathrm{~g} / \mathrm{kg})\end{array}$ & $\begin{array}{c}\text { Group-III Treated } \\
(2 \mathrm{~g} / \mathrm{kg})\end{array}$ & $\begin{array}{c}\text { Group-IV Treated } \\
(5 \mathrm{~g} / \mathrm{kg})\end{array}$ \\
\hline \multicolumn{5}{|l|}{ Hematology } \\
\hline Total $\mathrm{WBC}_{\mathrm{s}}\left(\times 10^{3} / \mu \mathrm{L}\right)$ & $7.97 \pm 0.13$ & $8.03 \pm 0.15$ & $7.35 \pm 0.23$ & $8.51 \pm 0.27$ \\
\hline $\mathrm{RBC}_{\mathrm{s}}\left(\times 10^{6} / \mu \mathrm{L}\right)$ & $7.79 \pm 0.21$ & $7.91 \pm 0.11$ & $7.60 \pm 0.20$ & $8.44 \pm 0.17$ \\
\hline Platelets $\left(\times 10^{3} / \mu \mathrm{L}\right)$ & $603 \pm 1.16$ & $656 \pm 2.09$ & $584 \pm 2.61$ & $764 \pm 3.17$ \\
\hline $\mathrm{Hb}(\mathrm{g} / \mathrm{dL})$ & $11.21 \pm 0.12$ & $11.39 \pm 0.23$ & $11.10 \pm 0.19$ & $12.10 \pm 0.29$ \\
\hline \multicolumn{5}{|c|}{ Normal range $(10-16 \mathrm{~g} / \mathrm{dL})$} \\
\hline \multicolumn{5}{|l|}{ Blood chemistry } \\
\hline ALT (U/L) & $43.1 \pm 1.31$ & $51.4 \pm 2.02$ & $42.33 \pm 2.44$ & $58.34 \pm 2.08$ \\
\hline \multicolumn{5}{|l|}{ Normal range (17-77) } \\
\hline $\operatorname{AST}(\mathrm{U} / \mathrm{L})$ & $157.1 \pm 1.33$ & $164.2 \pm 2.15$ & $145.31 \pm 3.14$ & $187.42 \pm 2.13$ \\
\hline \multicolumn{5}{|l|}{ Normal range (54-298) } \\
\hline \multicolumn{5}{|l|}{ Renal profile } \\
\hline Creatinine $(\mathrm{mg} / \mathrm{dL})$ & $0.37 \pm 0.02$ & $0.39 \pm 0.01$ & $0.34 \pm 0.03$ & $0.49 \pm 0.01$ \\
\hline \multicolumn{5}{|c|}{ Normal range $(0.2-0.9 \mathrm{mg} / \mathrm{dL})$} \\
\hline Urea $(\mathrm{mg} / \mathrm{dL})$ & $54 \pm 1$ & $61 \pm 2$ & $51 \pm 1$ & $63 \pm 2$ \\
\hline Uric acid (mg/dL) & $4.8 \pm 0.01$ & $5.1 \pm 0.02$ & $4.2 \pm 0.01$ & $5.4 \pm 0.01$ \\
\hline \multicolumn{5}{|l|}{ Lipide profile } \\
\hline Serum cholesterol & $133.54 \pm 2.31$ & $144.23 \pm 2.14$ & $128.22 \pm 2.13$ & $162.61 \pm 2.15$ \\
\hline \multicolumn{5}{|c|}{ Normal range $(150-220 \mathrm{mg} / \mathrm{dL})$} \\
\hline Serum triglycerides & $112.21 \pm 2.43$ & $114.22 \pm 2.17$ & $109.12 \pm 1.92$ & $119.28 \pm 2.25$ \\
\hline
\end{tabular}

conference of harmonization (ICH, 2005). The rate of heart beat was noted after administration of 0.001 , $0.01,0.1$ and $1 \mathrm{mg} / \mathrm{mL} \mathrm{GXH}$ on rabbit heart. The study demonstrated that GXH did not affect rate of heart beat (Figure 1f).

\section{CONCLUSION}

The parameters studied during acute toxicological evaluation of GXH led to conclusion that GXH can be used as safe oral drug excipient. It caused no toxicity signs in albino mice and rabbits during acute toxicology studies. Nevertheless, long term toxicological studies are demanding to estimate $\mathrm{LD}_{50}$ of GXH.

\section{ACKNOWLEDGEMENT}

Gulzar Muhammad gratefully acknowledges the Higher Education Commission of Pakistan (HEC) for providing the financial support under "Indigenous 5000 $\mathrm{PhD}$ fellowship" program. 


\section{DISCLOSURE STATEMENT}

The authors report no conflicts of interest

\section{REFERENCES}

Ashraf MU, Hussain MA, Muhammad G, Haseeb MT, Bashir S, Hussain SZ, Hussain I. A superporous and superabsorbent glucuronoxylan hydrogel from quince (Cydonia oblonga): Stimuli responsive swelling, on-off switching and drug release. Int J Biol Macromol. 2017;95:138-44.

Atyabi F, Sharma HL, Mohammad HAH, Fell JT. Controlled drug release from coated floating ion exchange resin beads. J Control Release. 1996;42(1):25-28.

Bum EN, Dawack DL, Schmutz M, Rakotonirina A, Rakotonirina SV, Portet C, Jeker A, Olpe HR, Herrling P. Anticonvulsant activity of Mimosa pudica decoction. Fitoterapia. 2004;75(34):309-11.

Chen J, Blevins WE, Park H, Park K. Gastric retention properties of superporous hydrogel composites. J Control Release. 2000;64(1-3):39-51.

Chen Z, Meng H, Xing G, Chen C, Zhao Y, Jia G, et al. Acute toxicological effects of copper nanoparticles in vivo. Toxicol Lett. 2006;163(2):109-120.

Dinda B, Ghosh B, Arima S, Sato N, Harigaya Y. Steroids and terpenoids from Mimosa pudica roots. J Indian Chem Soc. 2006;83(10):1044-46.

Good BT, Bowman CN, Davis RH. Modeling and verification of fluid-responsive polymer pumps for microfluidic systems. Chem Eng Sci. 2004;59(24):5967-74.

Gupta NV, Shivakumar HG. Preparation and characterization of superporous hydrogels as $\mathrm{pH}$-sensitive drug delivery system for pantoprazole sodium. Curr Drug Deliv. 2009;6(5):505-10.

Haseeb MT, Hussain MA, Yuk SH, Bashir S, Nauman M. Polysaccharides based superabsorbent hydrogel from Linseed: Dynamic swelling, stimuli responsive on-off switching and drug release. Carbohyd Polym. 2016;136:750-56.

Hoffman AS. Hydrogels for biomedical applications. Adv Drug Del Rev. 2012;64:18-23.
Hussain MA, Muhammad G, Jantan I, Bukhari SNA. Psyllium arabinoxylan: A versatile biomaterial for potential medicinal and pharmaceutical applications. Polym Rev. 2016;56(1):1-30.

International Conference on Harmonisation. ICH Guidance for Industry. S7A, safety pharmacology studies for human pharmaceuticals. Geneva: ICH; 2005.

Kay JH, Calandra JC. Interpretation of eye irritation tests. J Cosmet Sci. 1962;13:281-90.

Khalid MS, Kumar SJ, Suresh DK, Singh RK, Reddy IN, Kumar S. Evaluation of anti-diarrhoeal potential of ethanolic extract of Mimosa pudica leaves. Int J Green Pharm. 2011;5(1):75-78.

Liu DZ, Sheu MT, Chen CH, Yang YR, Ho HO. Release characteristics of lidocaine from local implant of polyanionic and polycationic hydrogels. J Control Release. 2007;118(3):33339.

Maderuelo C, Zarzuelo A, Lanao JM. Critical factors in the release of drugs from sustained release hydrophilic matrices. J Control Release. 2011;154(1):2-19.

Molina M, Contreras CM, Tellez-Alcantara P. Mimosa pudica may possess antidepressant actions in the rat. Phytomedicine. 1999;6(5):319-23.

Muhammad G, Hussain MA, Ashraf MU, Haseeb MT, Hussain SZ, Hussain I. Polysaccharide based superabsorbent hydrogel from Mimosa pudica: swelling-deswelling and drug release. RSC Adv. 2016;6(28):23310-17.

Muhammad G, Hussain MA, Jantan I, Bukhari SNA. Mimosa pudica L., a high-value medicinal plant as a source of bioactives for pharmaceuticals. Compr Rev Food Sci Food Saf. 2016;15(2):303-15.

Ponchel G, Irache JM. Specific and non-specific bioadhesive particulate system for oral delivery to the gastro-intestinal tract. Adv Drug Deliv Rev. 1998;34(2-3):191-219.

Sahgal G, Ramanathan S, Sasidhara S, Mordi MN, Ismail S, Mansor SM. Brine shrimp lethality and acute oral toxicity studies on Swietenia mahagoni (Linn.) Jacq. Seed methanolic extract. Pharmacognosy Res. 2010;2(4):215-20.

Saiyed ZM, Sengupta K, Krishnaraju AV, Trimurtulu G, Lau FC, Lugo JP. Safety and toxicological evaluation of Meritrim ${ }^{\circledR}$ : An herbal formulation for weight management. Food Chem Toxicol. 2015;78:122-29. 
Saraswat R, Pokharkar R. GCMS studies of Mimosa pudica. Int J Pharm Tech Res. 2012;4(1):93-98.

Zhang XZ, Wu DQ, Chu CC. Synthesis, characterization and controlled drug release of thermosensitive IPN-PNIPAAm hydrogels. Biomaterials. 2004;25(17):3793-805.
Zou X, Zhao X, Ye L. Synthesis of cationic chitosan hydrogel with long chain alkyl and its controlled glucose-responsive drug delivery behaviour. RSC Adv. 2015;5:96230-41.

Received for publication on $13^{\text {th }}$ February 2017 Accepted for publication on $02^{\text {nd }}$ January 2018 